\title{
Reciprocal Lateral Hypothalamic and Raphe GABAergic Projections Promote Wakefulness
}

\author{
Mary Gazea, ${ }^{1,2 *}$ Szabina Furdan, ${ }^{3 *}$ Péter Sere, ${ }^{3,4}$ Lukas Oesch, ${ }^{2,3}$ Benedek Molnár, ${ }^{3,4}{ }^{\circledR}$ Giuseppe Di Giovanni, ${ }^{5,6}$ \\ Lief E. Fenno, ${ }^{7}$ Charu Ramakrishnan, ${ }^{8}$ Joanna Mattis, ${ }^{7}$ Karl Deisseroth, ${ }^{7,9}{ }^{\circledR}$ Susan M. Dymecki, ${ }^{10}$ \\ ${ }^{10}$ Antoine R. Adamantidis, ${ }^{1,2 *}$ and Magor L. Lórincz ${ }^{3,4,5 *}$ \\ ${ }^{1}$ Centre for Experimental Neurology, Department of Neurology, Inselspital, University Hospital Bern, University of Bern, Bern 3010, Switzerland, \\ ${ }^{2}$ Department of Biomedical Research, Inselspital University Hospital Bern, University of Bern, Bern 3010, Switzerland, ${ }^{3}$ Department of Physiology, \\ Anatomy, and Neuroscience, University of Szeged, Szeged 6726, Hungary, ${ }^{4}$ Department of Physiology, University of Szeged, Szeged 6720, Hungary, \\ ${ }^{5}$ Neurosci ence Division, School of Bioscience, Cardiff University, Cardiff CF10 3AX, United Kingdom, ${ }^{6}$ Department of Physiology and \\ Biochemistry, University of Malta, MSD 2080, Malta, ${ }^{7}$ Departments of Psychiatry \& Behavioral Sciences and Bioengineering, Stanford University, \\ Stanford 94305, California, ${ }^{8} \mathrm{CNC}$ Program, Stanford University, Stanford 94305, California, ${ }^{9}$ Howard Hughes Medical Institute, Stanford \\ University, Stanford 94305, California, and ${ }^{10}$ Department of Genetics, Harvard Medical School, Boston 02115, Massachusetts
}

The lateral hypothalamus (LH), together with multiple neuromodulatory systems of the brain, such as the dorsal raphe nucleus (DR), is implicated in arousal, yet interactions between these systems are just beginning to be explored. Using a combination of viral tracing, circuit mapping, electrophysiological recordings from identified neurons, and combinatorial optogenetics in mice, we show that GABAergic neurons in the LH selectively inhibit GABAergic neurons in the DR, resulting in increased firing of a substantial fraction of its neurons that ultimately promotes arousal. These $\mathrm{DR}_{\mathrm{GABA}}$ neurons are wake active and project to multiple brain areas involved in the control of arousal, including the $\mathrm{LH}$, where their specific activation potently influences local network activity leading to arousal from sleep. Our results show how mutual inhibitory projections between the LH and the DR promote wakefulness and suggest a complex arousal control by intimate interactions between long-range connections and local circuit dynamics.

Key words: arousal; brain states; neuromodulation; inhibition; optogenetics; disinhibition

Significance Statement:

Multiple brain systems including the lateral hypothalamus and raphe serotonergic system are involved in the regulation of the sleep/wake cycle, yet the interaction between these systems have remained elusive. Here we show that mutual disinhibition mediated by long range inhibitory projections between these brain areas can promote wakefulness. The main importance of this work relies in revealing the interaction between a brain area involved in autonomic regulation and another in controlling higher brain functions including reward, patience, mood and sensory coding.

Received Nov. 10, 2020; revised Feb. 15, 2021; accepted Feb. 28, 2021.

Author contributions: M.L.L. and A.R.A. designed research; M.G., S.F., P.S., L.O., and B.M. performed research; M.G., S.F., L.O., and M.L.L. analyzed data; M.G., A.R.A. and M.L.L. edited the paper; M.G., A.R.A. and M.L.L wrote the paper; G.D.G., L.E.F., C.R., J.M., K.D. and S.M.D contributed unpublished reagents/analytic tools.

This work was supported by Hungarian Scientific Research Fund Grants NN125601 and FK123831 to M.LL.., Hungarian Brain Research Program Grant KTIA_NAP_13-2-2014-0014 to M.LL., National Institutes of Health R01 DA034022 to S.M. D., German Research Foundation GA 2410/1-1 to M.G., Human Frontier Science Program RGY0076/2012 to A.R.A., Swiss National Science Foundation Grant 31003A_ 156156 to A.R.A., and European Research Council Grant 725850 to A.R.A.t MCST grant N. R\&l 2013-01 EPILEFREE to G.D.G and Sz.F. M.L.L. is a grantee of the János Bolyai Fellowship. This work is dedicated to the loving memory of our friend and colleague István Ábrahám.

*M.G., S.F., A.R.A., and M.L.L. contributed equally to this work.

M. Gazea's present address: Concentris research management GmbH, Fürstenfeldbruck, D-82256, Germany. The authors declare no competing financial interests.

Correspondence should be addressed to Magor L. L'órincz at mlorincz@gmail.com or Antoine R. Adamantidis at antoine.adamantidis@dbmr.unibe.ch.

https://doi.org/10.1523/JNEUROSCI.2850-20.2021

Copyright $\odot 2021$ the authors

\section{Introduction}

Brain-wide neuronal activities are strongly modulated across sleep-wake states (Saper et al., 2010; Weber and Dan, 2016) attributable to the influence of neuromodulatory systems of the brainstem (Jones, 2020), basal forebrain (Fuller et al., 2011; Xu et al., 2015), and lateral hypothalamus (LH) (Bonnavion et al., 2016; Arrigoni et al., 2019). In this context, the LH stands both as an anatomic and a sleep-wake hub.

Various LH neuronal populations are known to modulate sleep-wake states (Saper et al., 2010; Weber and Dan, 2016), energy intake and reward (Bernardis and Bellinger, 1996; Stuber and Wise, 2016). Hypocretins/orexins (Hcrt/Ox) and Vgatexpressing neurons of the $\mathrm{LH}\left(\mathrm{LH}_{\mathrm{Vgat}}\right)$ control wakefulness (Adamantidis et al., 2007; Carter et al., 2009, 2012; Herrera et al., 2016; Venner et al., 2016). Optogenetic activation of $\mathrm{LH}_{\mathrm{Vgat}}$ 
neurons induced rapid arousal through direct modulation of the reticular thalamus and brainstem circuits in the locus coeruleus (LC) area (Herrera et al., 2016); concomitant to an inhibition of anterior hypothalamic sleep-promoting circuits (Venner et al., 2019). In contrast, activation of MCH neurons promotes REM, and to a lesser extent NREM, sleep (Verret et al., 2003; Jego et al., 2013; Konadhode et al., 2013; Tsunematsu et al., 2014). Yet, whether and how $\mathrm{LH}_{\mathrm{Vgat}}$ neurons also modulate the activity of other brainstem neuromodulatory circuits remain unclear.

$\mathrm{LH}_{\text {Vgat }}$ neurons are reciprocally connected to multiple brainstem nuclei (Bonnavion et al., 2016), including the dorsal raphe nucleus (DR) (Weissbourd et al., 2014). The DR is an appealing candidate for influencing sleep-wake states since its major neuromodulator serotonin rapidly influences sensory (Kapoor et al., 2016; Lottem et al., 2016), motor (Z. Liu et al., 2014; Correia et al., 2017; Seo et al., 2019), and cognitive (Miyazaki et al., 2011; Z. Liu et al., 2014; Cohen et al., 2015; Fonseca et al., 2015) functions. Importantly, the DR has been involved in the regulation of various pathophysiological functions, including depression, which is often accompanied by sleep disturbances (Lowry et al., 2008; Steiger and Pawlowski, 2019; Riemann et al., 2020). The largest fraction of DR neurons are nonserotonergic (Descarries et al., 1982), express the VGAT marker (Allers and Sharp, 2003), and project to various forebrain targets, including the $\mathrm{LH}$ (Bang and Commons, 2012). These $\mathrm{DR}_{\mathrm{VGAT}}$ neurons control food intake, and their activity increases in response to fasting (Nectow et al., 2017); however, their role in sleep-wake behavior remains to be examined.

Using combinatorial optogenetics and electrophysiological recordings from identified neurons, we show that $\mathrm{LH}_{\mathrm{GABA}}$ neurons selectively inhibit $\mathrm{DR}_{\mathrm{GABA}}$ neurons, resulting in disinhibition of a part of DR neurons ultimately leading to arousal. We found that $\mathrm{DR}_{\mathrm{GABA}}$ neurons are highly active during wakefulness compared with NREM and REM sleep. Selective activation of their projection to the $\mathrm{LH}$ area leads to wakefulness, highlighting the importance of reciprocal hypothalamus-brainstem long range circuits in the control of brain states and arousal.

\section{Materials and Methods}

All experimental procedures were performed according to the European Communities Council Directives of 1986 (86/609/EEC) and 2003 (2003/ $65 / C E$ ) for animal research and were approved by the Ethics Committee of the University of Szeged and University of Bern. Eighty adult (age $>2$ months) male mice were used in this study.

\section{Experimental design}

Viral targeting. For in vitro recordings, AAV1-CAG-ChR2-venusWPRE-SV40, AAV1-CAGS-flex-ChR2-tdTomato-WPRE-SV40 viruses (50-150 nl, Penn Vector Core; titer: $\left.5 \times 10^{12} \mathrm{gc} / \mathrm{ml}\right)$ were injected bilaterally in the LH (AP: $-1.4 \mathrm{~mm}, \mathrm{ML}: \pm 1 \mathrm{~mm}, \mathrm{DV}:-5.0$ to $5.4 \mathrm{~mm}$ ) of WT, GAD-GFP (Tamamaki et al., 2003), or Vgat-IRES-Cre (Vong et al., 2011) mice using a nanoinjector (Nanoliter 2000, WPI) connected to a glass pipette $(\sim 20 \mu \mathrm{m}$ diameter) at a rate of $1 \mathrm{nl} / \mathrm{s}$.

For in vivo optogenetic activation of $\mathrm{LH}_{\mathrm{VGAT}}$ projections to the $\mathrm{DR}$, one group of Vgat-IRES-Cre mice (Vong et al., 2011) received AAV1CAGGS-FLEX-CHR2-td tomato-SV40 or AAV2-EF1a-DIO-hChR2 (H134R)-eYFP, while the second group received AAV2-EF1a-DIOeYFP (control, all virus vectors were packaged at the Vector Core of the University of North Carolina at Chapel Hill, titers between $3 \times 10^{12}$ and $5 \times 10^{12} \mathrm{gc} / \mathrm{ml}$ ). For the intersectional optogenetic activation of DR neuronal subpopulations, Vgat-IRES-Cre (Vong et al., 2011) x Pet1-Flpe (Jensen et al., 2008) double-transgenic mice received AAVdj-EF1a-Foff/ Con-hChR2(H134R)-eYFP (Pet1-OFF/Vgat-ON), AAVdj-EF1a-Fon/ Con-hChR2(H134R)-eYFP (Pet1-ON/Vgat-ON), or AAVdj-EF1a-eYFP
(eYFP controls); 150-600 $\mathrm{nl}$ of each virus was injected bilaterally into the LH or into the DR (AP: -4.45 , ML: +1.2 , DV: -2.9 to -3.1 , at a $30^{\circ}$ angle). The virus suspension was infused with a micro-infusion pump (PHD Ultra, Harvard Apparatus) through a $28 \mathrm{G}$ stainless-steel cannula (Plastic One) at a rate of $0.1 \mu \mathrm{l}$ per minute.

Surgical procedures. Mice were anesthetized using 1\%-1.5\% (v/v) isoflurane, placed in a stereotaxic frame (model 900, David Kopf Instruments) on a heating pad (Supertech). For sleep studies, 8- to 10week-old male Vgat-IRES-Cre mice were chronically implanted with an optical fiber (200 $\mu \mathrm{m}, 0.39$ NA Core Multimode Optical Fiber, FT200EMT, TECS Clad, Thorlabs, inserted into zirconia ferrules, 1.25 $\mathrm{mm}$ OD; $230 \mu \mathrm{m}$ ID, Precision Fiber product) above the DR (AP -4.45 , ML 1.2, DV -2.9 from bregma at a $20^{\circ}$ mediolateral angle), which were fixated to the skull with C\&B-Metabond (Parkell). Four stainless-steel screw electrodes were inserted epidurally (two into both frontal cortices, two into parietal cortices) for the recording of EEG signals, and wire loops were sewn to both neck muscles for EMG recordings. The EEG/ EMG electrodes and optic fiber were secured to the skull with dental cement (Patterson Dental). After surgical procedures, mice received appropriate postoperative care: analgesics, Rimadyl (15 mg/kg), antiinflammatory drug, Dexafort $(2 \mathrm{mg} / \mathrm{kg})$, antibiotic, gentamicin $(5 \mathrm{mg} /$ $\mathrm{kg}$ ) and were allowed to recover for 2 weeks.

In vitro electrophysiology. Mice were deeply anesthetized and perfused through the heart with ice-cold cutting solution containing the following (in mM): $93 \mathrm{NMDG}, 2.5 \mathrm{KCl}, 1.2 \mathrm{NaH}_{2} \mathrm{PO}_{4}, 30 \mathrm{NaHCO}_{3}, 20$ HEPES, 25 glucose, $5 \mathrm{~N}$-acetyl-L-cysteine, $5 \mathrm{Na}$-ascorbate, $3 \mathrm{Na}$-pyruvate, $10 \mathrm{MgSO}_{4}$, and $0.5 \mathrm{CaCl}_{2}$. The same solution was used to cut coronal brainstem slices containing the DR at $4^{\circ} \mathrm{C}$ and for the initial storage of slices $\left(32^{\circ} \mathrm{C}-34^{\circ} \mathrm{C}\right.$ for $\left.12 \mathrm{~min}\right)$ following which the slices were stored in a solution containing the following (in $\mathrm{mm}$ ): $30 \mathrm{NaCl}, 2.5 \mathrm{KCl}, 1.2$ $\mathrm{NaH}_{2} \mathrm{PO}_{4}, 1.3 \mathrm{NaHCO}_{3}, 20$ HEPES, 25 glucose, $5 \mathrm{~N}$-acetyl-L-cysteine, 5 $\mathrm{Na}$-ascorbate, $3 \mathrm{Na}$-pyruvate, $3 \mathrm{CaCl}_{2}$, and $1.5 \mathrm{MgSO}_{4}$. For recording, slices were submerged in a chamber perfused with a warmed $\left(34^{\circ} \mathrm{C}\right)$ continuously oxygenated $\left(95 \% \mathrm{O}_{2}, 5 \% \mathrm{CO}_{2}\right)$ ACSF containing the following (in mM): $130 \mathrm{NaCl}, 3.5 \mathrm{KCl}, 1 \mathrm{KH}_{2} \mathrm{PO}_{4}, 24 \mathrm{NaHCO}_{3}, 1.5 \mathrm{MgSO}_{4}, 3$ $\mathrm{CaCl}_{2}$, and 10 glucose. DR neurons were visualized using standard DIC optics and recorded in whole-cell current-clamp mode using an EPC9 amplifier (Heka Elektronik). Patch pipettes (tip resistance, 4-5 $\mathrm{M} \Omega$ ) were filled with an internal solution containing the following (in $\mathrm{mM}$ ): $126 \mathrm{~K}$ gluconate, $4 \mathrm{KCl}, 4$ ATP-Mg, 0.3 GTP-Na $\mathrm{Na}_{2}, 10$ HEPES, 10 creatine-phosphate, and 8 biocytin, pH 7.25; osmolarity, 275 mOsm. The liquid junction potential $(-13 \mathrm{mV})$ was corrected offline. Access and series resistances were constantly monitored, and data from neurons with a $>20 \%$ change from the initial value were discarded. $\mathrm{DR}_{\mathrm{GABA}}$ neuron somata in GAD-GFP mice (Tamamaki et al., 2003) were targeted under epifluorescent illumination. Photostimulation was performed through the microscope objective using a blue LED light source $(0.5-0.8 \mathrm{~mW} /$ $\mathrm{mm}^{2}$, Thorlabs).

In vivo electrophysiology and juxtacellular labeling. To record the activity of DR neurons mice were anesthetized using 1\%-1.5\% (v/v) isoflurane (Forane), placed in a stereotaxic frame (model 900, David Kopf Instruments) on a heating pad (Supertech). A small craniotomy (1 $\mathrm{mm}$ diameter) was made over the DR (AP: $-4.75 \mathrm{~mm}$, ML: $0.2 \mathrm{~mm}$, DV: $-3.1 \mathrm{~mm}$ from bregma) leaving the dura mater intact. Glass electrodes (resistance: 10-25 $\mathrm{MOhm}$ ) were filled with saline containing $1.5 \%$ biocytin (Sigma Millipore). The electrode was lowered in a $15^{\circ}$ mediolateral angle to avoid the sagittal sinus. The activity of DR neurons was monitored using a Multiclamp 700B amplifier (Molecular Devices) operating in current-clamp mode (filtered between $100 \mathrm{~Hz}$ and $3 \mathrm{kHz}$ ). At the end of some recordings, neurons were filled with biocytin (Sigma Millipore) using 0.5-4 $\mathrm{nA}$ anodal current pulses of $500 \mathrm{~ms}$ duration, $50 \%$ duty cycle for 2-10 min as previously described (Pinault, 1996). For recording GABAergic neurons in the DR, the lateral wings were targeted, where most neurons are GABAergic (Allers and Sharp, 2003). These neurons possessed small ( $\leq 15 \mu \mathrm{m}$ diameter) oval somata and mean baseline firing rates $>5 \mathrm{~Hz}$ (Allers and Sharp, 2003).

Data acquisition. Before the start of the experiment, the animals were habituated to a 3-m-long fiber optic patch cord with protective tubing (Thorlabs) that was connected to the chronically implanted optical 
A

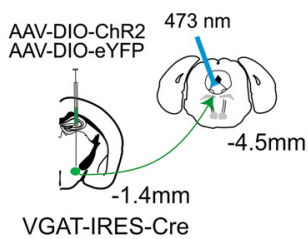

E

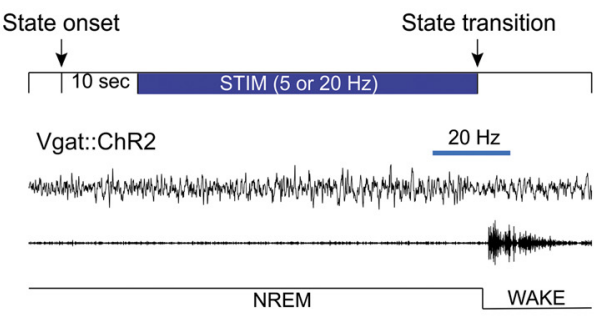

B

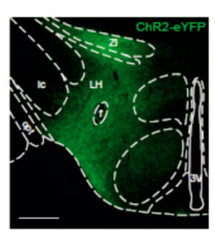

F

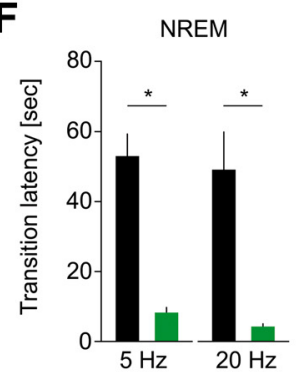

C

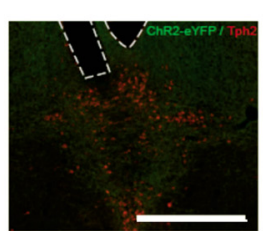

D

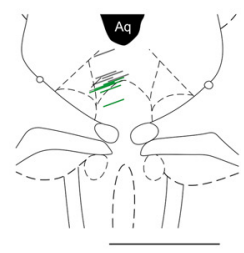

G

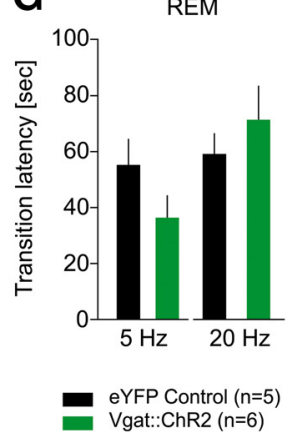

Figure 1. Stimulation of $\mathrm{LH}_{\mathrm{GABA}}$ fibers in the DR promotes wakefulness. $A$, Schematics of the experimental design: AAV-EF1a-DI0-ChR2-eYFP or AAV-EF1a-DI0-eYFP was injected in the LH of Vgat-cre mice. Following 4 weeks of expression, $\mathrm{LH}_{\mathrm{GABA}}$ fibers were photostimulated in the DR with simultaneous polysomnographic recordings for sleep stage scoring. $\boldsymbol{B}$, Example ChR2-eYFP expression in the LH. Fluorescent image overlaid on the stereotaxic atlas (AP: 4.45). C, Location of the optical fiber in the DR used for photostimulation. Merged fluorescent image showing $\mathrm{LH}_{\text {GABA }}$ fibers expressing ChR2-eYFP (green) and TPH immunohistochemistry (red) to indicate the location of TPH-synthetizing serotonergic neurons within the DR. D, Location of all implanted optical fibers in 11 mice. Green lines indicate Vgat::ChR2-expressing mice $(n=6)$. Gray lines indicate eYFP controls $(n=5)$. Aq, Aqueduct. $\boldsymbol{E}$, Top, Schematic experimental timeline for sleepstage specific photostimulation. Bottom, Representative EEG/EMG traces illustrate behavioral response to optogenetic stimulation. Note the rapid EEG desynchronization and EMG activation on photostimulation indicating an NREM-to-wake transition. $\boldsymbol{F}$, Latency of NREM-to-wake transition caused by the photostimulation of $\mathrm{LH}_{\mathrm{GABA}}$ axons in the DR. $\boldsymbol{G}$, Latency of REM-to-wake transition caused by the photostimulation of $\mathrm{LH}_{\mathrm{GABA}}$ axons in the DR. ${ }^{*} p<0.05$.

fiber with a zirconia sleeve (Precision Fiber Products) and an EEG/EMG cable for 1 week. Subsequently, a $24 \mathrm{~h}$ baseline polysomnographic recording was obtained without any optogenetic manipulations. EEG and EMG signals were sampled with an AM Systems 3500 amplifier at 512 $\mathrm{Hz}$ and digitized with a National Instruments USB X DAQ device. EEG and EMG data were recorded with the SleepScore software (View Point). All experiments took place between 10:00 A.M. and 2:00 P.M. (Zeitgeber time 3-7).

For unit recordings in freely moving animals, mice were habituated to optical patch cords and an electrode board head stage (RHD2132, Intan Technologies) for at least $4 \mathrm{~d}$. Subsequently, a $24 \mathrm{~h}$ baseline polysomnographic recording was obtained without optogenetic manipulations to ensure that the animals recovered a normal sleep-wake cycle. Tetrode signals were acquired at $20 \mathrm{kHz}$ with an open-source acquisition software (Open Ephys) via a digitizing head stage (RHD2132) and a multichannel DAQ board (Open Ephys, Intan Technologies). Opto-tagging was performed by applying short blue light pulses to the DR (10 times $5 \mathrm{~ms}$ pulses, every $30 \mathrm{~s}$ ). Light-responsive cells were identified based on their spiking activity within $3 \mathrm{~ms}$ of the application of blue light.

EEG and EMG recordings. Sleep-wake stages were manually scored based on EEG/EMG signal characteristics as described previously (Jego et al., 2013). Briefly, wakefulness was scored when low-amplitude desynchronized EEG activity was accompanied by high, tonic muscle activity with phasic bursts in the EMG. NREM sleep was defined by the presence of synchronized, high-amplitude oscillations in the $\delta$ frequency band $(0.5-4 \mathrm{~Hz})$ and low EMG tone. REM sleep was scored when the EEG showed pronounced theta oscillations with an almost complete absence of EMG tone, except for short twitches. The $24 \mathrm{~h}$ baseline recordings were scored in epochs of $5 \mathrm{~s}$, whereas state-specific optogenetic stimulation recordings were scored at an epoch duration of $1 \mathrm{~s}$.

Optogenetic activation during polysomnographic recordings. For in vivo optogenetic stimulation experiments, the patch cord was connected to a $473 \mathrm{~nm}$ DPSS laser (Laserglow Technologies) via a FC/PC connector (250 $\mu \mathrm{m}, 30126 \mathrm{G} 2-250$, Thorlabs). The laser output was set to a power output of $10 \mathrm{~mW}$ from the tip of the optic fiber. Trains of $5 \mathrm{~ms}$ pulses at 5 or $20 \mathrm{~Hz}$ were applied to $\mathrm{LH}_{\mathrm{VGAT}}$ fibers or DR Pet1-OFF/Vgat-ON neurons and fibers using a Master-9 pulse generator (AM Systems).
State-specific optical activation was performed based on visual inspection of online EEG and EMG signal parameters. For NREM and REM sleep-specific optogenetic activation, pulse trains were applied through the patch cord and optic fiber when the animal spent at least $10 \mathrm{~s}$ in NREM or REM sleep. The optogenetic stimulation was performed throughout the NREM or REM episode until the mouse transitioned to another state. Afterwards, the animal was left undisturbed to cycle between NREM sleep, REM sleep, and wakefulness for 2-3 cycles before the next NREM or REM sleep episode was optically stimulated. A total of 9 NREM and REM sleep episodes per animal were optogenetically stimulated for each frequency (5 and $20 \mathrm{~Hz}$ ).

Immunohistochemistry following sleep studies. At the end of the experiments, the mice were deeply anesthetized with an intraperitoneal injection of pentobarbital ( $250 \mathrm{mg} / \mathrm{kg}$, Streuli Pharma) and transcardially perfused with $5 \mathrm{ml}$ cold saline $(0.9 \% \mathrm{NaCl})$ followed by $20 \mathrm{ml} 4 \%$ formaldehyde (Grogg Chemie). Subsequently, the brains were removed and stored in formaldehyde overnight at $4^{\circ} \mathrm{C}$ for postfixation. The next day, the brains were transferred into PBS containing 30\% sucrose before freezing. The brains were cut into $30 \mu \mathrm{m}$ sections with a cryostat (Hyrax C 25, Carl Zeiss) and collected in PBS with $0.1 \%$ Triton A-100 (Sigma Millipore), PBST.

For immunostaining, the sections were first incubated for $1 \mathrm{~h}$ at room temperature in a blocking solution containing 4\% BSA (Sigma Millipore) in PBS-T. Then the tissue was incubated with anti-GFP (1:5000, A0262, Invitrogen) and anti-Tph2 (1:400, ABN60, Merck) for $24 \mathrm{~h}$. Afterwards, the sections were washed for $5 \times 5 \mathrm{~min}$ in PBS-T and then incubated with DyLight 488 and AlexaFluor-555 secondary antibody (1:500 dilution, A96947 for eYFP, Invitrogen; 1:500, A21428 for $\mathrm{Tph} 2$, Invitrogen) at room temperature for $1 \mathrm{~h}$. The sections were washed $2 \times 10 \mathrm{~min}$ in PBS-T and 2-10 min in PBS and then mounted on glass slides. Coverslips were fixed on the slides with Fluoromount (F4680, Sigma Millipore). Photomicrographs were taken using a confo$\mathrm{cal}$ microscope. For display, the image brightness and contrast were moderately adjusted in Adobe Photoshop CC.

Immunohistochemistry following in vitro recordings. Following in vivo electrophysiological recordings, slices were immersed in $4 \% \mathrm{PFA}$ in $0.1 \mathrm{M} \mathrm{PB}, \mathrm{pH} 7.4$, at $4^{\circ} \mathrm{C}$ for at least $12 \mathrm{~h}$. After several washes with $0.1 \mathrm{M}$ $\mathrm{PB}$, slices were embedded in $10 \%$ gelatin, and further sectioned into 

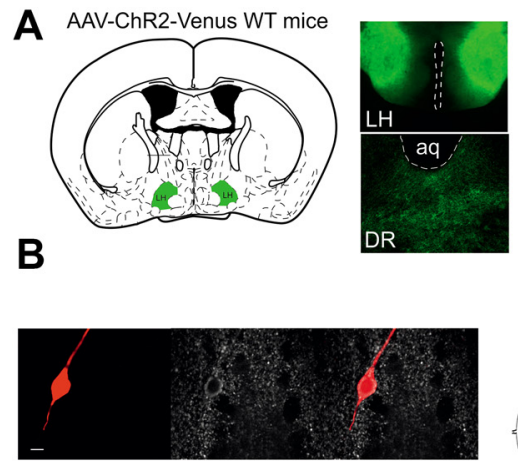

E

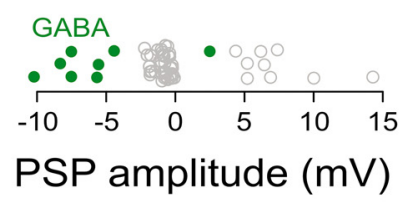

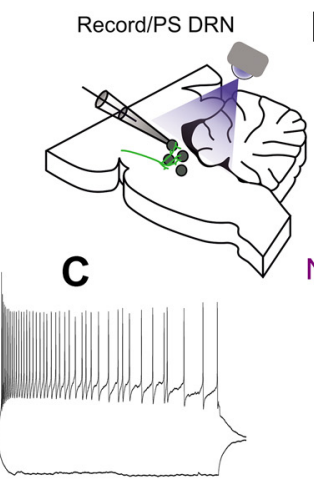

F $\quad \frac{\downarrow 20 \mathrm{mV}}{200 \mathrm{~ms}}$

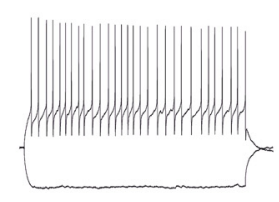

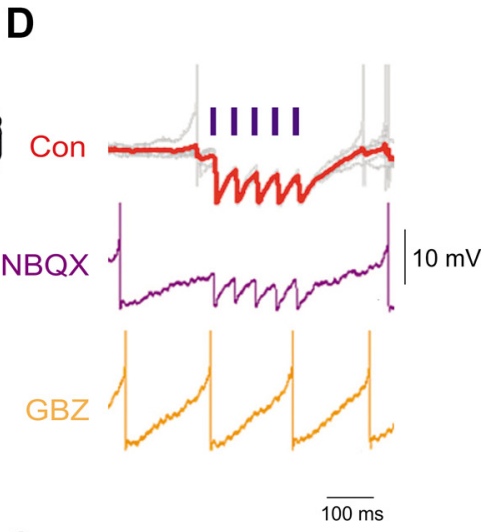

G

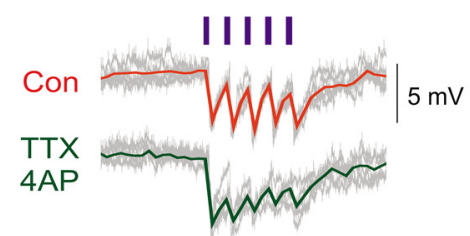

Figure 2. LH projections synaptically target DR neurons. $A$, Schematic of the experimental design: AAV-ChR2-Venus injection in the LH of WT mice leads to prominent $C h R_{2}$ expression in DR-projecting axons. Four weeks after the infection, local axons of LH neurons are photostimulated in the DR with simultaneous whole-cell patch-clamp recordings in identified DR neurons. $\boldsymbol{B}$, Fluorescent images (streptavidin, GABA immunostaining, merged) of a DR $\mathrm{GABA}_{\text {na }}$ neuron responding to $\mathrm{LH}$ axonal photostimulation. $\boldsymbol{C}$, Membrane potential responses of the neuron in $\boldsymbol{B}$ to hyperpolarizing and depolarizing current steps show fast action potential output with moderate frequency adaptation. $\boldsymbol{D}$, The photostimulation of LH axons leads to monosynaptic IPSPs that are resistant to iGluR blockade (NBQX), but blocked by SR95531 (i.e., gabazine [GBZ]). $E$, Distribution of PSP amplitudes in all the neurons recorded $(n=51)$. Green circles represent identified DR GABA $_{2}$ neurons. $\boldsymbol{F}$, Membrane potential responses of a physiologically identified $D R_{G A B A}$ neuron. $\boldsymbol{G}$, The photostimulation of LH axons leads to IPSPs in the neuron shown in $\boldsymbol{F}$ that persist following the application of TTX and 4-AP.

slices of 50-70 $\mu \mathrm{m}$ thickness in the cold PB using a vibratome VT1000S (Leica Microsystems). Coronal sections were subjected to freeze-thaw over liquid nitrogen after cryoprotecting in $10 \%$ and $20 \%$ sucrose. The recorded cells were first visualized with incubation in Cy3-conjugated streptavidin (Jackson ImmunoResearch Laboratories) for $2 \mathrm{~h}$, diluted at 1:500 in TBS (Sigma Millipore). After examination by epifluorescence microscopy (Olympus BX60), the sections containing the soma of the labeled neurons were incubated in 10\% normal horse serum in TBS to block nonspecific antibody-binding sites. Free-floating sections were incubated in primary antibodies dissolved in TBS containing $0.1 \%$ Triton X-100 (Sigma Millipore) for overnight at room temperature $\left(22^{\circ}\right.$ $\mathrm{C})$. The following primary antibodies were used: anti-5HT-Rb (1:1000, Jackson ImmunoResearch Laboratories) and anti-GABA-Rb (1:1000, Jackson ImmunoResearch Laboratories). After several washes in TBS, the immunoreactions were visualized with Dylight649-DARb (1:400, Jackson ImmunoResearch Laboratories) secondary antibodies. Finally, the sections were mounted in Vectashield mounting medium (VectorLaboratories). Images were taken by confocal microscope (Olympus FV1000).

Immunohistochemistry following in vivo single-unit recordings. After experiments, the animal was quickly perfused through the heart with 50 $\mathrm{ml}$ of PBS followed by $50 \mathrm{ml} 4 \%$ PFA in $0.1 \mathrm{~m} \mathrm{~PB}$. Following perfusion, brains were postfixed overnight and stored in $0.1 \mathrm{M} \mathrm{PB}$ with $0.05 \%$ sodium azide at $4^{\circ} \mathrm{C}$ as a preservative. The tissue was sectioned in $\mathrm{PB}$ at $50-70 \mu \mathrm{m}$ on a vibratome (Leica Microsystems, VT 1000S). Coronal sections were permeabilized in $0.3 \%$ Triton X-100 and incubated in Cy3 or Alexa-488-conjugated streptavidin (1:500; Jackson ImmunoResearch Laboratories) for $2 \mathrm{~h}$ at room temperature in TBS. Images were taken by confocal microscope (Olympus FV1000).

\section{Statistical analysis}

Data analysis was performed using Spike2 (Cambridge Electronic Design), OriginPro 8.5 (MicroCal), IgorPro (WaveMetrics), MATLAB (The MathWorks), and Prism (GraphPad) software. The data were tested for normality with the Shapiro-Wilk and the KolmogorovSmirnov tests and accordingly analyzed using parametric or nonparametric methods. We used three-way ANOVA to test for frequency (5 vs $20 \mathrm{~Hz}$, within-group comparisons) and opsin (eYFP controls vs ChR2-expressing mice, between-groups comparisons) effects in the latencies to transition to another state from NREM or REM sleep of state-specific optogenetic activation experiments. PSPs evoked by photostimulation were detected in $V_{\mathrm{m}}$ recordings using a threshold of $2 \times \mathrm{SD}$ in a $\pm 50 \mathrm{~ms}$ time window following photostimulation. Action potentials in extracellular recordings were detected in Spike2 using a straightforward level threshold. Firing rate histograms were computed for each photostimulation trial of each neuron. The control period was defined as $0.5 \mathrm{~s}$ before photostimulation. All data are displayed as averages \pm SEM.

The firing rate change of single units on photostimulation was assessed by subtracting the average spike rate during the $10 \mathrm{~s}$ preceding the stimulation from the average spike rate during optogenetic activation. To test for significant modulation, 9999 stimulation onsets were randomly drawn from each single unit's activity time series, and the firing rate change across these random onsets was calculated. If the actual firing rate difference was $>95 \%$ or $<5 \%$ of the randomly calculated ones, the firing of the neuron was significantly modulated during this photostimulation. Inhibited or disinhibited neurons showed a significant decrease or increase, respectively, of their firing rate during $>50 \%$ of all photostimulations. Neurons whose firing rate was significantly modulated during $<50 \%$ of all optogenetic stimulations are reported as unresponsive.

\section{Results}

$\mathrm{LH}_{\mathrm{GABA}}$ projections to the DR promote wakefulness

A subpopulation of $\mathrm{LH}_{\mathrm{VGAT}}$ (vesicular GABA and glycine transporter) neurons causally promotes arousal from NREM sleep (Herrera et al., 2016; Venner et al., 2016, 2019). Here, we tested the role of $\mathrm{LH}_{\mathrm{VGAT}}$ projections to the $\mathrm{DR}$ in the control of sleep-wake behavior. To deliver opsins to $\mathrm{LH}_{\mathrm{VGAT}}$ neurons, VGAT-Cre mice were stereotactically injected with AAV2-EF1aDIO-eYFP (control) or AAV2-EF1a-DIO-hChR2(H134R)-eYFP (ChR2-EYFP) in the LH for in vivo optogenetic activation 
experiments (see Materials and Methods; Fig. $1 A, B)$. Mice were then implanted with EEG/EMG electrodes for recording and quantification of sleep-wake states together with an optic fiber above the DR (see Materials and Methods; Fig. 1C,D). Statespecific optogenetic activation of $\mathrm{LH}_{\mathrm{VGAT}}$ fibers in the DR was triggered manually after at least $10 \mathrm{~s}$ in stable NREM or REM sleep. Blue light $(473 \mathrm{~nm})$ was delivered to the DR at 5 or $20 \mathrm{~Hz}$ ( $5 \mathrm{~ms}$ pulses) (see Herrera et al., 2016) in both control (eYFP) and ChR2-expressing animals continuously until a state transition occurred (Fig. 1E). Interestingly, optogenetic activation of $\mathrm{LH}_{\mathrm{VGAT}}$ projections to the $\mathrm{DR}$ during NREM sleep led to a rapid arousal at both 5 and $20 \mathrm{~Hz}$ within $<7$ s (Fig. 1F; $p<0.0001$, three-way ANOVA), whereas optical activation of these fibers failed to significantly change REM sleep duration (Fig. 1G). These results extend previous mechanisms for $\mathrm{LH}_{\mathrm{VGAT}}$-induced arousal to DR neurons in the brainstem.

$\mathrm{DR}_{\mathrm{GABA}}$ neurons receive monosynaptic inputs from $\mathrm{LH}_{\mathrm{GABA}}$ neurons

We previously found that $\mathrm{LH}_{\mathrm{GABA}}$ neurons send long-range projections to various brainstem nuclei, including the DR (Herrera et al., 2016). In order to determine the downstream circuitries mediating this rapid arousal response, we mapped $\mathrm{LH}_{\mathrm{GABA}}$ efferents using ChR2-assisted circuit mapping to functionally characterize this LH-DR circuit (Fig. 2A). We infected $\mathrm{LH}$ neurons regardless of their neurochemical identity with ChR2 using a viral construct (AAV1-CAG-ChR2-venus-WPRESV40) optimized for in vitro photostimulation of axons (Petreanu et al., 2009). We found that photostimulation of $\mathrm{ChR}_{2}$ expressing $\mathrm{LH}$ terminals in the $\mathrm{DR}$ evoked IPSPs $(-7.9 \pm 1.03 \mathrm{mV}$ peak amplitude with a $10.91 \pm 2.41 \mathrm{~ms}$ decay time) in 7 DR cells (14\%) recorded (Fig. $2 D, E)$, while EPSPs of $7.58 \pm 0.9 \mathrm{mV}$ peak amplitude with a $11.07 \pm 2.46 \mathrm{~ms}$ decay time were recorded in 10 (20\%) DR cells (Fig. 2E). No detectable PSPs could be recorded in the remaining population $(n=$ $34,66 \%)$. All DR neurons exhibiting IPSPs following LH axonal photostimulation were confirmed to be GABAergic (Fig. 2B,E) by post hoc immunohistochemistry $(n=5)$ or by recording $\mathrm{DR}_{\mathrm{GABA}}$ neurons in GAD-GFP mice ( $n=3$, see Materials and Methods), one identified $D_{\mathrm{GABA}}$ neuron received EPSPs (Fig. 2E). The IPSPs could be abolished by SR95531 (i.e., gabazine, $n=5$ of 5 cells, $100 \%$ ) but not NBQX ( $n=0$ of 5 , $0 \%$; Fig. $2 D$ ), suggesting that these are monosynaptic pathways implicating GABAa receptors. This result was further confirmed by the recording of similar IPSPs on photostimulation of LH axon terminals in the presence of TTX and 4animals.
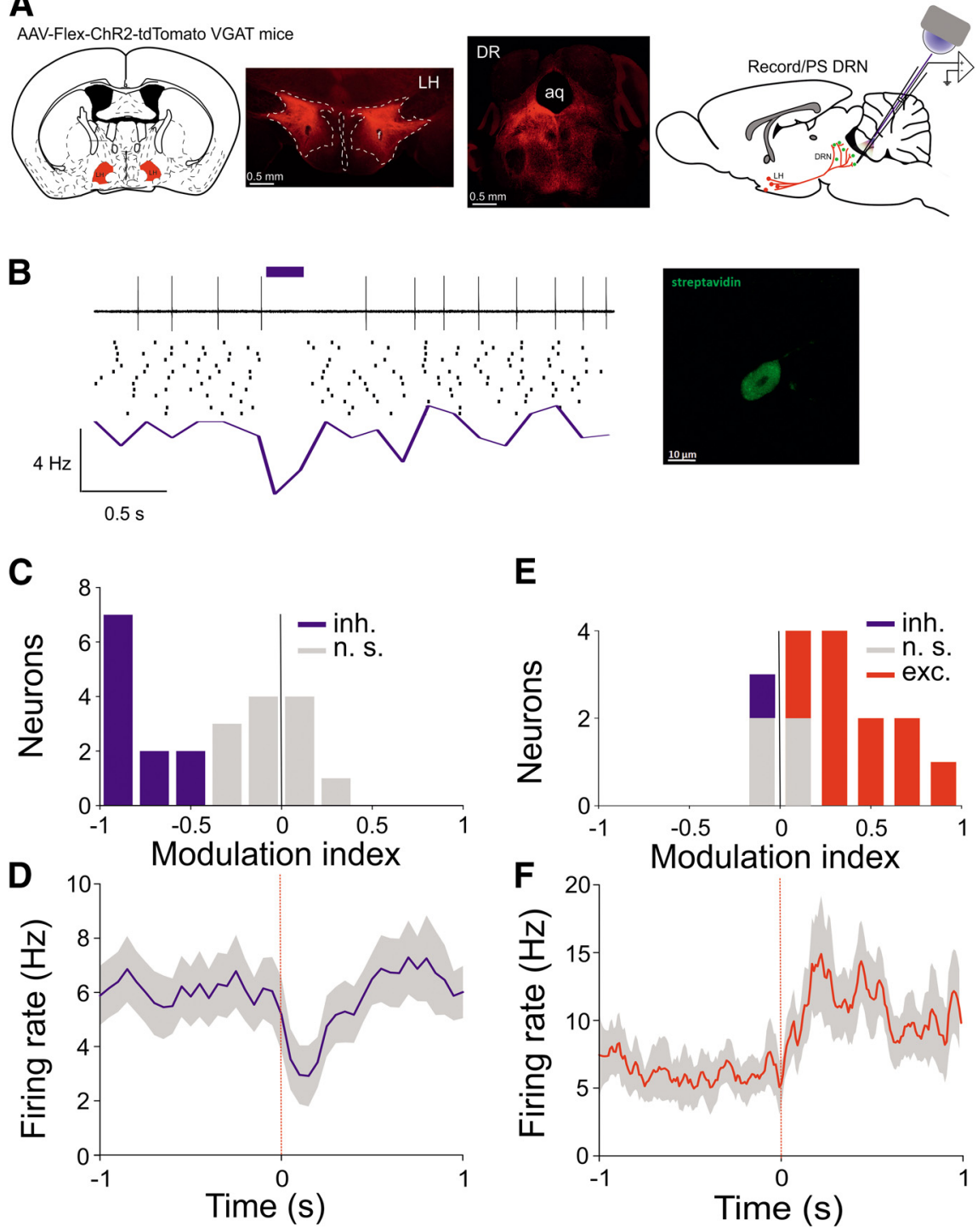

Figure 3. $\mathrm{LH}_{\mathrm{GABA}}$ inputs control DR neuronal activity. $\boldsymbol{A}$, Schematic of the experimental design: AAV-Flex-ChR2-td tomato injection in the LH of VGAT mice leads to prominent ChR2 expression in DR-projecting axons. Four weeks after the infection, local axons of $\mathrm{LH}_{\mathrm{GABA}}$ neurons are photostimulated in the DR with simultaneous single-unit juxtacellular recoding/labeling. $\boldsymbol{B}$, Example of spontaneous activity of a $\mathrm{DR}_{\mathrm{GABA}}$ neuron and its response to local photostimulation of $\mathrm{LH}_{\mathrm{GABA}}$ axons. Top, Singletrial raw data aligned on photostimulation onset (blue horizontal bar, $5 \mathrm{~mW}, 10 \mathrm{~ms}$ pulses at $50 \mathrm{~Hz}$ ). Middle, Raster plot in which each tic is a single-unit spike and each row represents a single trial. Red line indicates photostimulation onset. Bottom, Peristimulus time histogram (PSTH) of the unit shown above. Right, Fluorescent pictures showing the neuron recorded in $\boldsymbol{B}$ filled with Neurobiotin using the juxtacellular filling technique. $\boldsymbol{C}$, Modulation index of all recorded neurons under anesthesia. $\boldsymbol{D}$, Grand average PSTH of all neurons recorded under anesthesia. $\boldsymbol{E}$, Modulation index of all recorded neurons in awake animals (inh, inhibited; exc, excited). $\boldsymbol{F}$, Grand average PSTH of all neurons recorded neurons in awake

AP (mean IPSP amplitude: control: $6.5 \pm 0.6 \mathrm{mV}$, TTX/4AP: $6.8 \pm 0.7 \mathrm{mV}, n=6$ neurons; Fig. $2 F, G)$. When neurons were held at membrane potentials close to action potential initiation threshold, photostimulation of $\mathrm{LH}$ axons also led to a prominent suppression of firing $(12.66 \pm 6.65 \mathrm{~Hz}$ vs 0 $\mathrm{Hz}, \mathrm{MI}-1.0, n=3$ neurons) because of the presence of IPSPs (Fig. 2D). This suppression of firing was fully abolished when IPSPs were blocked by gabazine ( $n=3$ of 3 ; Fig. $2 D)$. These results show that the LH to DR monosynaptic projections are functional, can be either inhibitory or excitatory, and that $\mathrm{DR}_{\mathrm{GABA}}$ neurons are preferentially inhibited by $\mathrm{LH}_{\mathrm{GABA}}$ fibers. 
A

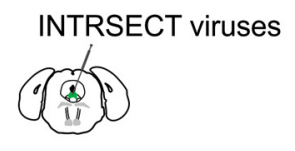

B

Pet1-Flpe x Vgat-Cre mice

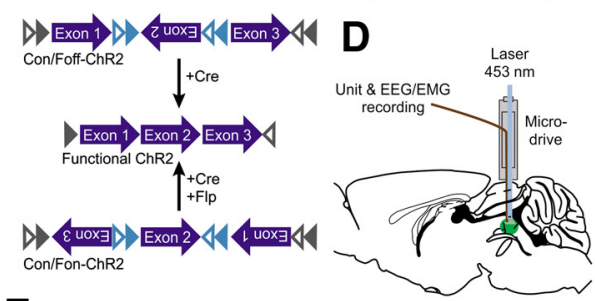

E

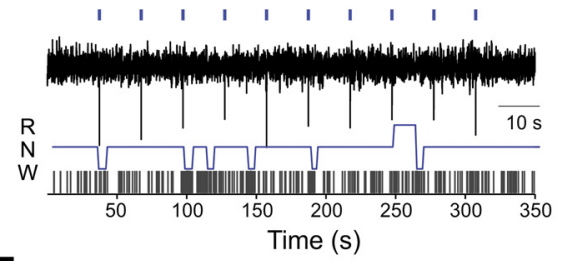

F
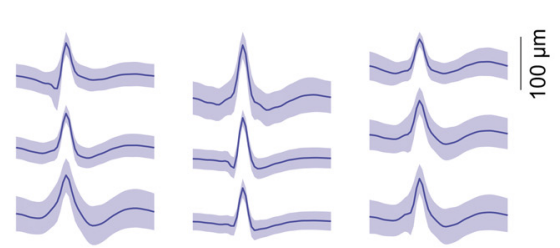

G
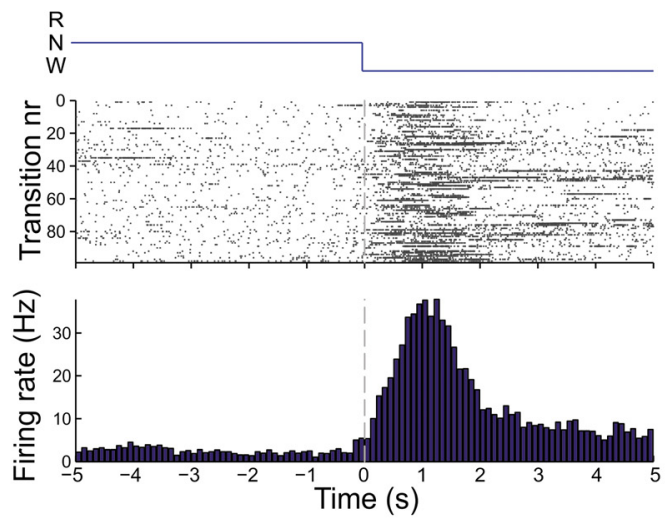

H
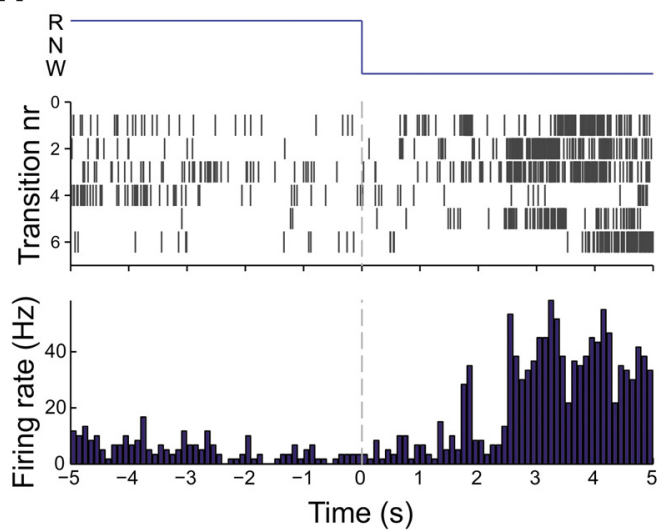

I

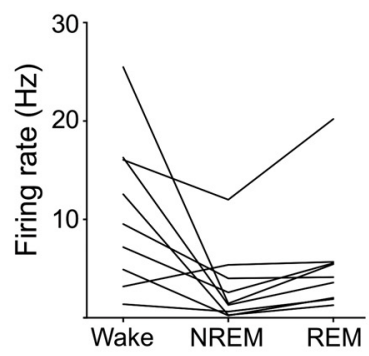

J

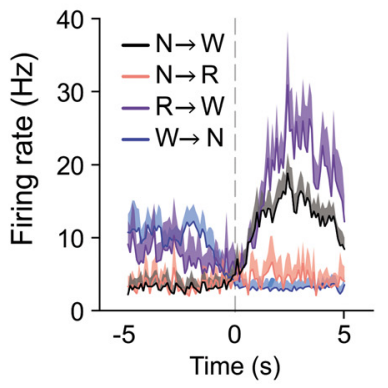

Figure 4. The activity of optogenetically identified $D R_{G A B A}$ neurons is modulated across the sleep-wake cycle. $A$, Schematics of intersectional viral strategy: ChR2-Con/off-eYFP was targeted to DR neurons in Pet1 ${ }^{\text {Fipe }}$-Vgat ${ }^{\text {Cre }}$ double-transgenic mice. B, Schematics of INTRSECT system (Fenno et al., 2014): FRT (gray triangles) and lox sites (light blue triangles) were introduced in intronic sequences within the ChR2 ORF allowing for directional control of these ORFs. In the Con/Foff-ChR2 construct, the presence of Cre recombinase produces a functional ChR2. However, the presence of Flp recombinase would invert the exons, thus yielding an inactivated state of ChR2. In the Con/Fon-ChR2 construct, the presence of both Cre and Flp recombinase is required to

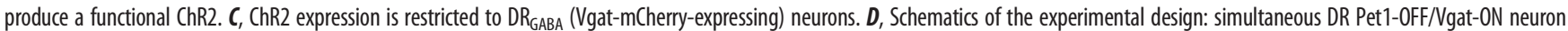
and EEG recordings in behaving mice. E, Example recording of a DR Pet1-0FF/Ngat-ON neuron throughout various sleep/wake states. Top, Raw trace voltage recording shows clear action potential firing on photostimulation (blue ticks). Bottom, Hypnogram and spike ticks of the neuron showed above. W, Wake; R, REM; N, NREM. $\boldsymbol{F}$, Averaged spike waveforms of optogenetically identified DR Pet1-OFF/Ngat-ON neurons ( $n=9$ neurons from $n=4$ mice). DR Pet1-OFF/Ngat-ON neurons were identified by their immediate firing in response to pulses of blue light generated by a $453 \mathrm{~nm}$ laser (10 pulses of $5 \mathrm{~ms}$ every $30 \mathrm{~s}$ ). $\mathbf{G}, \boldsymbol{H}$, Raster plot of a DR Pet1-OFF/Ngat-ON neuron during NREM-to-wake transitions $(\boldsymbol{G})$ and REM-to-wake transitions $(\boldsymbol{H})$ with spike ticks of the neuron (top) and PSTH of the neuron across all transitions (bottom). I, Firing rates of the 9 DR Pet1-0FF/Ngat-ON neurons across wakefulness, NREM, and REM sleep. J, PSTH (mean \pm SEM) of DR Pet1-OFF/Vgat-ON neurons during the different sleep state transitions.

\section{$\mathrm{LH}_{\mathrm{GABA}}$ to $\mathrm{DR}$ projections can rapidly suppress the activity of $\mathrm{DR}_{\mathrm{GABA}}$ neurons}

To test for functional connections from $\mathrm{LH}_{\mathrm{GABA}}$ projections to $\mathrm{DR}$ neurons, we recorded extracellular single-unit activity from morphologically identified neurons in the DR of anesthetized VGAT-cre mice infected with AAV1-CAGGS-FLEX-CHR2-tdTOM-SV40 in the $\mathrm{LH}$ while photostimulating $\mathrm{ChR}$-expressing $\mathrm{LH}_{\mathrm{GABA}}$ axons in the DR (5 light pulses of $10 \mathrm{~ms}$ at $20 \mathrm{~Hz}, 5 \mathrm{~mW}$; Fig. $3 A$ ).

When comparing the activity of DR neurons on $\mathrm{LH}_{\mathrm{GABA}}$ axonal photostimulation, we found a rapid suppression (peak suppression: $42.37 \pm 5.94 \%$; Fig. $3 B$ ) of neuronal activity (baseline firing: $7.72 \pm 6.43 \mathrm{~Hz}$, baseline firing rate after photostimulation: $5.37 \pm 6.77 \mathrm{~Hz}, n=25, p<0.001$, Wilcoxon's signed rank test; Fig. $3 C, D$ ). We identified the morphology of 8 neurons recorded and filled with the juxtacellular labeling technique. These neurons were classified as putative $\mathrm{DR}_{\mathrm{GABA}}$ neurons based on their high baseline firing rate $(\geq 6 \mathrm{~Hz})$ morphology and location within the DR (see Materials and Methods). These results show that $\mathrm{LH}_{\mathrm{GABA}}$ neurons exert an inhibitory action onto putative $\mathrm{DR}_{\mathrm{GABA}}$ neurons.
We next explored the effect of stimulating $\mathrm{LH}_{\mathrm{GABA}}$ fibers in the DR in awake, head-restrained animals while recording the activity of multiple single units in the DR (see Materials and Methods). Comparison of the activity of DR neurons recorded in the presence and absence of $\mathrm{LH}_{\mathrm{GABA}}$ axonal photostimulation (5 light flashes of $10 \mathrm{~ms}$ at $20 \mathrm{~Hz}, 5 \mathrm{~mW}$ ) further confirmed the suppressive effect in a subset of DR neurons ( 2 of $12,17 \%$ ), while the activity of the remaining neurons was increased (10 of 12 , $83 \%)$. The overall activity of DR neurons was slowly ( $\sim 200 \mathrm{~ms})$, but persistently $(\sim 1 \mathrm{~s})$ increased (baseline firing: $7.67 \pm 6.87 \mathrm{~Hz}$, baseline firing after photostimulation: $10.98 \pm 8.920 \mathrm{~Hz}, n=12$, $p<0.001$, Wilcoxon's signed rank test; Fig. 3E,F).

\section{The activity of identified $\mathrm{DR}_{\mathrm{GABA}}$ neurons is brain state- dependent}

To target $\mathrm{DR}_{\mathrm{GABA}}$ neurons in the $\mathrm{DR}$, we made use of the intersectional virus approach (Fenno et al., 2014). In brief, the INTRSECT system (intronic recombinase sites enabling combinatorial targeting) consists of orthogonal Cre and Flp recognition sites (lox and FRT sites, respectively) that are inserted into 
A

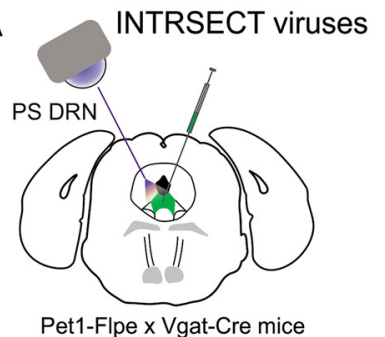

C NREM-specific stimulations

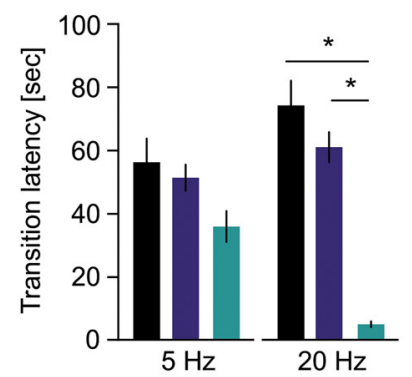

B
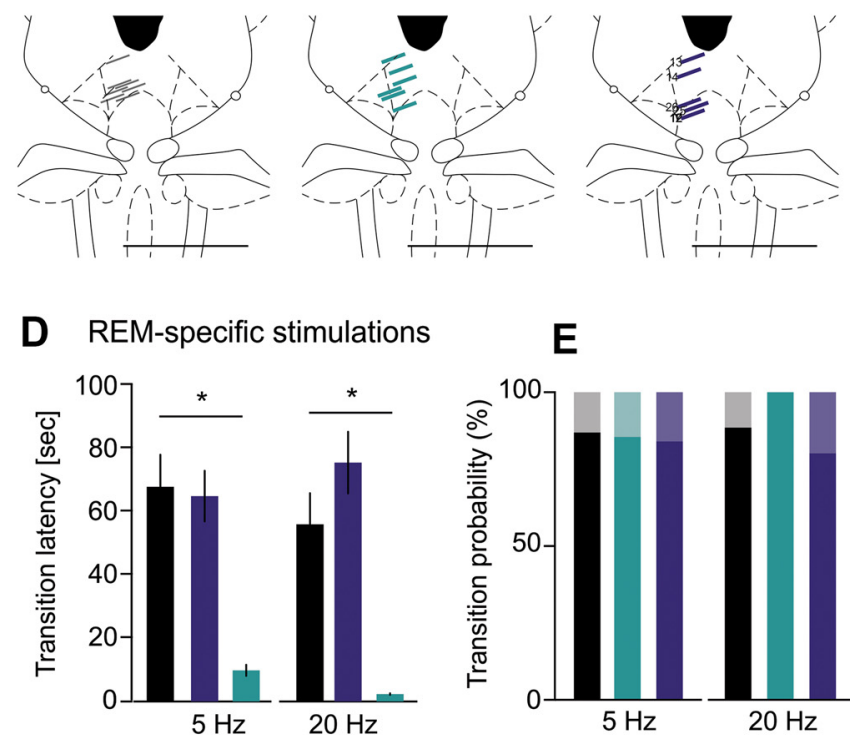

Control $(n=6)$
Pet $1^{\text {ON }}-$ Vgat
Pet $1^{\text {OF }}-$ Vgat $^{\text {ON }}(n=6)$
E

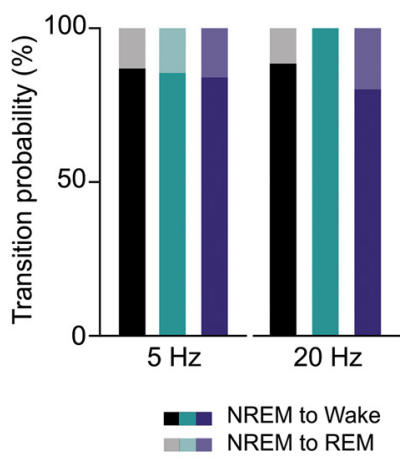

Figure 5. Stimulation of $D R_{G A B A}$ neurons promotes wakefulness. $A$, Schematic of the experimental strategy: various intersectional viral constructs carnying the coding sequence of either eYFP (control) or ChR2 are injected in the DR of Pet1 ${ }^{\text {Flpe }}$-VGAT ${ }^{\text {Cre }}$ double-transgenic mice. The DR is photostimulated 4 weeks after infection. B, Location of the fiber-optic canulae in all the animals used. Left, Gray lines indicate control. Middle, Green lines indicate Pet1-OFF/VGAT-ON. Right, Blue lines indicate Pet1-ON/NGAT-ON. C, Latency of NREM-to-wake transition caused by the photostimulation of the DR. D, Latency of REM-to-wake transition caused by the photostimulation of the DR. $E$, State transition probabilities at 5 versus $20 \mathrm{~Hz}$ photostimulation for all three viral constructs. ${ }^{*} p<0.05$.

synthetic introns of the ChR2-eYFP open reading frame (ORF) within an adeno-associated viral construct (AAVdj). The starting direction of the ORF fragments between the lox and FRT recognition sites defines whether the presence of Flp and/or Cre recombinases is required to produce a functional opsin (ChR2eYFP or eYFP; Fig. $4 A, B$ ).

Here, we used this approach to exclude the possibility that GABAergic markers (Vgat) are coexpressed with serotonergic neurons (Huang et al., 2019; Ren et al., 2019; Okaty et al., 2020). To this end, Pet ${ }^{\text {Flpe }}{ }^{\text {-Vgat }}{ }^{\text {Cre }}$ double-transgenic mice (Jensen et al., 2008; Vong et al., 2011) were injected with Cre-ON/Flp-OFF or Cre-ON/Flp-ON intersectional viruses (Fig. $4 A, B$ ), which allowed the targeting of ChR2-eYFP to distinct subpopulations of the DR that expressed Pet1, a transcription factor predominantly found in 5-HT neurons (Hendricks et al., 1999), and Vgat (Pet1-ON/Vgat-ON) or Vgat only (Pet1-OFF/Vgat-ON). The Pet1-OFF/Vgat-ON GFP-positive neurons colocalized with Vgat neurons that were cotransfected with a Cre-dependent mCherry virus (Fig. 4C).

To investigate whether the activity of $\mathrm{DR}_{\mathrm{GABA}}$ neurons is modulated across sleep-wake states, we performed opto-tag unit recording of putative DR Pet1-OFF/Vgat-ON neurons while simultaneously conducting EEG and EMG recordings in freely moving Pet $1^{\mathrm{Flpe}}-\mathrm{Vgat}^{\mathrm{Cre}}$ mice (see Materials and Methods; Fig. $4 D$ ). These neurons were identified by their immediate increase in spiking in response to short blue light pulses (10 times $5 \mathrm{~ms}$ pulses, every $30 \mathrm{~s}$ ) delivered to the DR via an optic fiber. A total of 9 optogenetically identified Pet1-OFF/Vgat-ON neurons (9 of 66 cells from 4 animals; Fig. $4 E, F)$ were recorded across the sleep-wake cycle (Fig. 4F). The activity of Pet1-OFF/ VGAT-ON neurons was modulated across sleep-wake states (Fig. 4G-I; NREM vs wake/REM: $p<0.05$, Friedman nonparametric test). Indeed, their firing activity increased significantly on arousal compared with the $5 \mathrm{~s}$ before the transition occurred (i.e., when the muscle tone was still low; Fig. 4G,H,J; NREM-to-wake: $p<0.01$; REM-to-wake: $p<$ 0.05 , paired $t$ tests). In turn, the firing activity decreased when the mice were at the onset of NREM sleep (wake-toNREM: $p<0.01$, paired $t$ test), whereas on the other hand, the transition from NREM to REM sleep was not marked by a substantial change in firing activity (Fig. $4 J$ ).

\section{Wake-promoting effect of $\mathrm{DR}_{\mathrm{GABA}}$ neurons}

Next, we investigated whether Pet1-OFF/VGAT-ON neurons in the DR were causally involved in arousal control. For this, we optogenetically activated DR Pet1-OFF/Vgat-ON neurons during NREM sleep (see Materials and Methods; Fig. 5C). Consistent with our correlative data, we found that photostimulation of DR Pet1-OFF/VGAT-ON neurons induced a rapid arousal from NREM sleep when light pulses were delivered at 20 $\mathrm{Hz}$ compared with controls $(p<0.0001$, three-way ANOVA; Pet1-OFF/VGAT-ON vs Control: $p<0.0001$, Dunnett's multiple comparison's post hoc test), whereas $5 \mathrm{~Hz}$ stimulation frequency did not decrease the latency to wakefulness transitions ( $n=6$ animals per group; Fig. $5 C$ ). The probability of REM sleep onset decreased on optogenetic activation of Pet1-OFF/VGAT-ON neurons during NREM sleep (Fig. $5 E$ ), suggesting an implication in REM sleep onset. However, both 5 and $20 \mathrm{~Hz}$ stimulation frequencies during REM sleep led to an immediate arousal from REM sleep in Pet1-OFF/ Vgat-ON mice (Fig. $5 D ; p<0.0001$, three-way ANOVA; Pet1OFF/VGAT-ON vs Control: $p<0.0001$, at both 5 and $20 \mathrm{~Hz}$, Dunnett's multiple comparison's post hoc test). As expected, optogenetic activation of Pet1-ON/VGAT-ON neurons ( $n=6$ animals) did not alter sleep-wake behavior compared with controls $(n=6$ animals; Fig. 5D,E). 

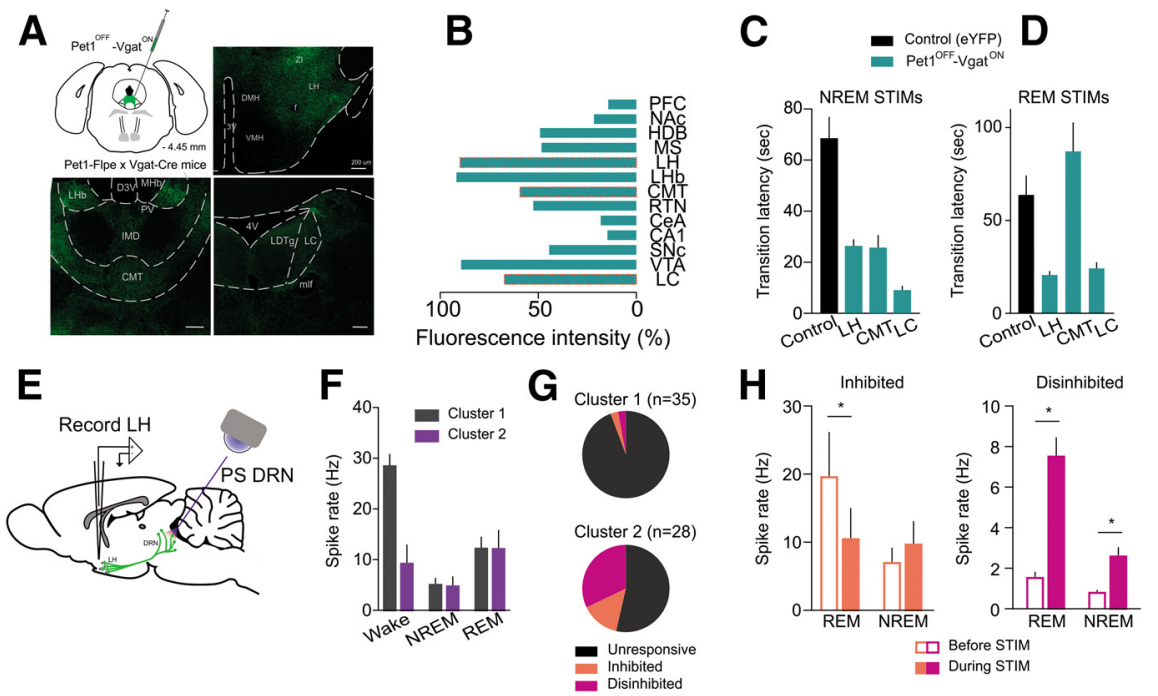

Figure 6. $D R_{G A B A}$ neurons promote arousal through disinhibition in the LH. $A$, Top left, Schematic of the experimental design:

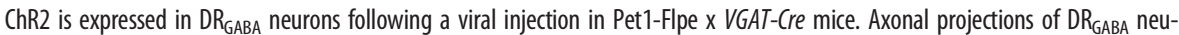
rons express ChR2 in various DR target areas, including the LH (top right), CMT (bottom left), and LC (bottom right). $\boldsymbol{B}$, Normalized intensity of the fluorescent eYFP signal in various projection areas of the DR. HDB, Horizontal diagonal band of Brocca; MS, medial septum; LHb, lateral habenula; RTN, thalamic reticular nucleus; CA1, hippocampus CA1 region. C, Latency of NREM-to-wake transition caused by photostimulation of $\mathrm{DR}_{\mathrm{GABA}}$ projections in the LH, CMT, and LC. $\boldsymbol{D}$, Latency of REM-to-wake transition caused by photostimulation of $\mathrm{DR}_{\mathrm{GABA}}$ projection targets ( $\mathrm{LH}, \mathrm{CMT}, \mathrm{LC}$ ). $\boldsymbol{E}$, Schematic of the experimental design: ChR2-expressing Pet1-0FF/Vgat-ON neurons are photostimulated in the DR while single units are recorded in the LH of freely moving mice. $\boldsymbol{F}$, Activity of all recorded LH neurons during various sleep-wake stages differentiates two clusters of neurons: Cluster 1 contains wake active neurons, whereas Cluster 2 neurons do not show significant firing rate increases during the awake state. $\boldsymbol{G}$, Pie chart of all Cluster 1 and 2 LH neurons constructed on the basis of their response to the photostimulation of $D R_{G A B A}$ neurons. $\boldsymbol{H}$, Effect of $D R_{G A B A}$ photostimulation on the state-dependent firing of inhibited (left) and disinhibited (right) neurons. ${ }^{*} p<0.05$.

\section{$\mathrm{DR}_{\mathrm{GABA}}$ neurons promote wakefulness through disinhibition in $\mathrm{LH}$}

To identify potential sleep-wake centers that may mediate the arousal promotion of $\mathrm{DR}_{\mathrm{GABA}}$ neurons, we performed a ChR2assisted functional circuit mapping. Animals were prepared as described above. We found that DR Pet1-OFF/VGAT-ON strongly innervated major sleep-wake centers, such as the LC, the VTA, the centromedial thalamic nucleus (CMT), and the LH (Fig. 6A,B). To further understand the reciprocal connection between the DR and the $\mathrm{LH}$, we performed optogenetic statespecific stimulations of Pet1-OFF/VGAT-ON projecting fibers in the LH. We found that optogenetic stimulation $(20 \mathrm{~Hz})$ of DR Pet1-OFF/VGAT-ON projections to the LH reproduced the arousal-inducing effect that was observed during somatic optogenetic activation (Fig. 6C,D; NREM sleep: $p<0.0001$, threeway ANOVA; Control vs LH stimulation: $p<0.001$, Dunnett's multiple comparisons post hoc test; REM sleep: $p<0.0001$, three-way ANOVA; Control vs LH stimulation: $p<0.001$, Dunnett's multiple comparisons post hoc test). Interestingly, optogenetic activation of Pet1-OFF/VGAT-ON projections in the LC area, a predominant wake-promoting center, resulted in a similar effect (Control vs LC stimulation: NREM sleep: $p<0.0001$; REM sleep: $p<0.001$, Dunnett's multiple comparisons post hoc test), whereas optogenetic stimulation of Pet1-OFF/VGAT-ON projections in the CMT led to an arousal only from NREM sleep, but not from REM sleep (Control vs CMT stimulation: NREM sleep: $p<0.001$; REM sleep: not significant, Dunnett's multiple comparisons post hoc test), in line with a previous study highlighting a role of the CMT in NREM sleep regulation (Gent et al., 2018) (Fig. 6C,D).

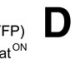

To further delineate the mechanism by which DR Pet1-OFF/VGAT-ON neurons induce arousal via the $\mathrm{LH}$, we performed single-unit recordings in the LH while simultaneously recording EEG/EMG and conducting optical stimulations of ChR2-expressing Pet1OFF/VGAT-ON neurons using a similar preparation as described above (see Materials and Methods; Fig. 6E). First, we clustered all the cells that we recorded in the $\mathrm{LH}$ according to their sleep-wake discharge profiles; recorded cells separated into two clusters, with one cluster showing maximal activity during wakefulness (55\% of cells from 2 animals; Fig. $6 F, G)$, while the second cluster showed maximal activity during both REM sleep and wakefulness (45\% of cells from 2 animals; Fig. $6 F$, $G)$. Cells from both clusters were less active during NREM sleep (Fig. 6F). Interestingly, during optogenetic stimulation of DR Pet1-OFF/VGAT-ON neurons, cells from Cluster 1 barely changed their firing rate, whereas half of the cells from the second cluster significantly modulated their firing activity in response to DR Pet1-OFF/ VGAT-ON neuronal activation (Fig. $6 G$ ). In particular, a major part of responsive cells from Cluster 2 was disinhibited by the optogenetic activation of DR Pet1-OFF/VGAT ON neurons, whereas a few cells were inhibited (Fig. 6G,H; $p<0.05$, three-way ANOVA). These results show that the activation of $\mathrm{DR}_{\mathrm{GABA}}$ neurons disinhibits the majority of LH neurons and promotes wakefulness.

\section{Discussion}

In this study, we show that activation of $\mathrm{LH}_{\mathrm{GABA}}$ axons in the DR promote wakefulness through a local release of GABA that rapidly suppresses activity of identified $\mathrm{DR}_{\mathrm{GABA}}$ neurons but indirectly activates other non-GABAergic DR neurons. In addition, we found that the activity of $\mathrm{DR}_{\mathrm{GABA}}$ neurons is state-dependent, whereas activation of $\mathrm{DR}_{\mathrm{GABA}}$ neurons disinhibits the majority of $\mathrm{LH}$ neurons to promote wakefulness. This wake-promoting effect of optogenetic activation of the $\mathrm{LH}_{\mathrm{GABA}}-\mathrm{DR}_{\mathrm{GABA}}$ circuit promotes rapid wakefulness selectively during NREM sleep, consistent with their activity profile across sleep-wake states (Hassani et al., 2010; Herrera et al., 2016). These findings identify a $\mathrm{LH}_{\mathrm{GABA}}-\mathrm{DR}_{\mathrm{GABA}}$ feedback loop that is essential for rapid alteration of global brain states and facilitation of wakefulness.

Using viral tracing and in vitro $\mathrm{ChR}_{2}$-assisted circuit mapping, we show that a subset of $\mathrm{LH}_{\mathrm{GABA}}$ neurons establishes monosynaptic connections to DR neurons. Functional analysis of this mapping revealed that $\mathrm{LH}_{\mathrm{GABA}}$ neurons exerts a $\mathrm{GABA}_{\mathrm{A}^{-}}$ mediated inhibitory action on $\mathrm{DR}_{\mathrm{GABA}}$ neurons leading to rapid NREM sleep-to-wake transitions. The precise neurochemical identity of this subset of DR-projecting $\mathrm{LH}_{\mathrm{GABA}}$ neurons remains to be established in light of the numerous subpopulations among inhibitory neurons of the LH (Mickelsen et al., 2017).

Local GABA release evoked by optogenetic activation of $\mathrm{LH}_{\mathrm{GABA}}$ axons in the DR promotes wakefulness suppressing the 
activity of $\mathrm{DR}_{\mathrm{GABA}}$ neurons. This occurs through a direct synaptic inhibition of $\mathrm{DR}_{\mathrm{GABA}}$ neurons mediated by $\mathrm{GABA}_{\mathrm{A}}$ receptors and leads to a prominent suppression of firing in $\mathrm{DR}_{\mathrm{GABA}}$ neurons in vivo. Consistent with these in vivo recordings, we show that the activity of identified $\mathrm{DR}_{\mathrm{GABA}}$ cells is strongly modulated across NREM sleep-to-wake transitions, and optogenetic activation of the $\mathrm{LH}_{\mathrm{GABA}}-\mathrm{DR}$ circuit promotes rapid wakefulness selectively during NREM sleep, but not during REM sleep. This result is in line with previous studies reporting sleep/ wake transitions on optogenetic activation of $\mathrm{LH}_{\mathrm{GABA}}$ fibers in the medial septum, LC, reticular thalamic nucleus, and ventrolateral preoptic area (Herrera et al., 2016; Venner et al., 2016, 2019). Our results demonstrate that $\mathrm{LH}_{\mathrm{GABA}}$ neurons directly inhibit $\mathrm{DR}_{\mathrm{GABA}}$ neurons, and this probably results in a disinhibition of various DR neurons. Revealing the exact targets of this disinhibition awaits further investigation and are hard to predict given the extreme neurochemical and physiological diversity of the raphe nuclei (Domonkos et al., 2016; Szőnyi et al., 2016; Sos et al., 2017). A phasic increase in 5-HT neuron activity can rapidly and prominently affect cortical activity (Lottem et al., 2016) and thus may lead to brain state changes. However, recently, the selective tonic activation of $\mathrm{DR}_{5-\mathrm{HT}}$ neurons has been shown to promote sleep, whereas burst stimulation induces wakefulness (Oikonomou et al., 2019). In light of the present results, it is possible that the phasic activity changes of DR neurons and their consequences at the cortical level at least partly originate from the $\mathrm{LH}_{\mathrm{GABA}}$ neuron activation during sleep-to-wake transitions.

$\mathrm{DR}_{\mathrm{GABA}}$ neuronal stimulation also promoted wakefulness, possibly by suppressing or activating local sleep- or wake-promoting neurons in the $\mathrm{LH}$, respectively. One may speculate that GABA release from $\mathrm{DR}_{\mathrm{GABA}}$ synapses could suppress the activity of sleep-promoting neurons, including REM sleep-promoting MCH neurons (Jego et al., 2013; Konadhode et al., 2013; Tsunematsu et al., 2014), REM active $\mathrm{LH}_{\mathrm{VGAT}}$ neurons (Hassani et al., 2010; Oesch et al., 2020), and REM-active Lh6x GABA neurons from the ventral zona incerta (K. Liu et al., 2017). In contrast, it could inhibit local inhibitory circuits that would result in the activation of the wake-promoting hypocretins/orexins neurons (Adamantidis et al., 2007), or wake-active $\mathrm{LH}_{\mathrm{VGAT}}$ neurons (Hassani et al., 2010; Herrera et al., 2016; Oesch et al., 2020). Whether and how this dual modulatory activity operates during the sleep-wake cycle await further investigation.

Together, a brain area involved in energy balance and arousal can affect the activity of the DR, an area involved in the control of higher brain functions, including reward, patience, mood, and sensory coding, suggesting a potential route for interactions between metabolic states and brain states.

\section{References}

Adamantidis AR, Zhang F, Aravanis AM, Deisseroth K, de Lecea L (2007) Neural substrates of awakening probed with optogenetic control of hypocretin neurons. Nature 450:420-424.

Allers KA, Sharp T (2003) Neurochemical and anatomical identification of fast- and slow-firing neurones in the rat dorsal raphe nucleus using juxtacellular labelling methods in vivo. Neuroscience 122:193-204.

Arrigoni E, Chee MJ, Fuller PM (2019) To eat or to sleep: that is a lateral hypothalamic question. Neuropharmacology 154:34-49.

Bang SJ, Commons KG (2012) Forebrain GABAergic projections from the dorsal raphe nucleus identified by using GAD67-GFP knock-in mice. J Comp Neurol 520:4157-4167.

Bernardis LL, Bellinger LL (1996) The lateral hypothalamic area revisited: ingestive behavior. Neurosci Biobehav Rev 20:189-287.
Bonnavion P, Mickelsen LE, Fujita A, de Lecea L, Jackson AC (2016) Hubs and spokes of the lateral hypothalamus: cell types, circuits and behaviour. J Physiol 594:6443-6462.

Carter ME, Adamantidis A, Ohtsu H, Deisseroth K, de Lecea L (2009) Sleep homeostasis modulates hypocretin-mediated sleep-to-wake transitions. J Neurosci 29:10939-10949.

Carter ME, Brill J, Bonnavion P, Huguenard JR, Huerta R, de Lecea L (2012) Mechanism for Hypocretin-mediated sleep-to-wake transitions. Proc Natl Acad Sci USA 109:E2635-E2644.

Cohen JY, Amoroso MW, Uchida N (2015) Serotonergic neurons signal reward and punishment on multiple timescales. eLife 4:e06346.

Correia PA, Lottem E, Banerjee D, Machado AS, Carey MR, Mainen ZF (2017) Transient inhibition and long-term facilitation of locomotion by phasic optogenetic activation of serotonin neurons. eLife 6:e20975.

Descarries L, Watkins KC, Garcia S, Beaudet A (1982) The serotonin neurons in nucleus raphe dorsalis of adult rat: a light and electron microscope radioautographic study. J Comp Neurol 207:239-254.

Domonkos A, Nikitidou Ledri L, Laszlovszky T, Cserep C, Borhegyi Z, Papp E, Nyiri G, Freund TF, Varga V (2016) Divergent in vivo activity of nonserotonergic and serotonergic VGluT3-neurones in the median raphe region. J Physiol 594:3775-3790.

Fenno LE, Mattis J, Ramakrishnan C, Hyun M, Lee SY, He M, Tucciarone J, Selimbeyoglu A, Berndt A, Grosenick L, Zalocusky KA, Bernstein H, Swanson H, Perry C, Diester I, Boyce FM, Bass CE, Neve R, Huang ZJ, Deisseroth K (2014) Targeting cells with single vectors using multiplefeature Boolean logic. Nat Methods 11:763-772.

Fonseca MS, Murakami M, Mainen ZF (2015) Activation of dorsal raphe serotonergic neurons promotes waiting but is not reinforcing. Curr Biol 25:306-315.

Fuller PM, Sherman D, Pedersen NP, Saper CB, Lu J (2011) Reassessment of the structural basis of the ascending arousal system. J Comp Neurol 519:933-956.

Gent TC, Bandarabadi M, Herrera CG, Adamantidis AR (2018) Thalamic dual control of sleep and wakefulness. Nat Neurosci 21:974-984.

Hassani OK, Henny P, Lee MG, Jones BE (2010) GABAergic neurons intermingled with orexin and $\mathrm{MCH}$ neurons in the lateral hypothalamus discharge maximally during sleep. Eur J Neurosci 32:448-457.

Hendricks T, Francis N, Fyodorov D, Deneris ES (1999) The ETS domain factor Pet-1 is an early and precise marker of central serotonin neurons and interacts with a conserved element in serotonergic genes. J Neurosci 19:10348-10356.

Herrera CG, Cadavieco MC, Jego S, Ponomarenko A, Korotkova T, Adamantidis A (2016) Hypothalamic feedforward inhibition of thalamocortical network controls arousal and consciousness. Nat Neurosci 19:290-298.

Huang KW, Ochandarena NE, Philson AC, Hyun M, Birnbaum JE, Cicconet M, Sabatini BL (2019) Molecular and anatomical organization of the dorsal raphe nucleus. eLife 8:e46464.

Jego S, Glasgow SD, Herrera CG, Ekstrand M, Reed SJ, Boyce R, Friedman J, Burdakov D, Adamantidis AR (2013) Optogenetic identification of a rapid eye movement sleep modulatory circuit in the hypothalamus. Nat Neurosci 16:1637-1643.

Jensen P, Farago AF, Awatramani RB, Scott MM, Deneris ES, Dymecki SM (2008) Redefining the serotonergic system by genetic lineage. Nat Neurosci 11:417-419.

Jones BE (2020) Arousal and sleep circuits. Neuropsychopharmacology 45:620.

Kapoor V, Provost AC, Agarwal P, Murthy VN (2016) Activation of raphe nuclei triggers rapid and distinct effects on parallel olfactory bulb output channels. Nat Neurosci 19:271-282.

Konadhode RR, Pelluru D, Blanco-Centurion C, Zayachkivsky A, Liu M, Uhde T, Glen WB Jr, van den Pol AN, Mulholland PJ, Shiromani PJ (2013) Optogenetic stimulation of $\mathrm{MCH}$ neurons increases sleep. J Neurosci 33:10257-10263.

Liu K, Kim J, Kim DW, Zhang YS, Bao H, Denaxa M, Lim SA, Kim E, Liu C, Wickersham IR, Pachnis V, Hattar S, Song J, Brown SP, Blackshaw S (2017) Lhx6-positive GABA-releasing neurons of the zona incerta promote sleep. Nature 548:582-587.

Liu Z, Zhou J, Li Y, Hu F, Lu Y, Ma M, Feng Q, Zhang JE, Wang D, Zeng J, Bao J, Kim JY, Chen ZF, El Mestikawy S, Luo M (2014) Dorsal raphe neurons signal reward through 5-HT and glutamate. Neuron 81:1360-1374. 
Lottem E, Lorincz ML, Mainen ZF (2016) Optogenetic activation of dorsal raphe serotonin neurons rapidly inhibits spontaneous but not odorevoked activity in olfactory cortex. J Neurosci 36:7-18.

Lowry CA, Hale MW, Evans AK, Heerkens J, Staub DR, Gasser PJ, Shekhar A (2008) Serotonergic systems, anxiety, and affective disorder: focus on the dorsomedial part of the dorsal raphe nucleus. Ann NY Acad Sci 1148:86-94.

Mickelsen LE, Kolling FW, Chimileski BR, Fujita A, Norris C, Chen K, Nelson CE, Jackson AC (2017) Neurochemical heterogeneity among lateral hypothalamic hypocretin/orexin and melanin-concentrating hormone neurons identified through single-cell gene expression analysis. eNeuro 4:ENEURO.0013-17.2017.

Miyazaki K, Miyazaki KW, Doya K (2011) Activation of dorsal raphe serotonin neurons underlies waiting for delayed rewards. J Neurosci 31:469479.

Nectow AR, Schneeberger M, Zhang H, Field BC, Renier N, Azevedo E, Patel B, Liang Y, Mitra S, Tessier-Lavigne M, Han MH, Friedman JM (2017) Identification of a brainstem circuit controlling feeding. Cell 170:429442.e411.

Oesch LT, Gazea M, Gent TC, Bandarabadi M, Gutierrez Herrera C, Adamantidis AR (2020) REM sleep stabilizes hypothalamic representation of feeding behavior. Proc Natl Acad Sci USA 117:19590-19598.

Oikonomou G, Altermatt M, Zhang RW, Coughlin GM, Montz C, Gradinaru V, Prober DA (2019) The serotonergic raphe promote sleep in zebrafish and mice. Neuron 103:686-701.e688.

Okaty BW, Sturrock N, Escobedo Lozoya Y, Chang Y, Senft RA, Lyon KA, Alekseyenko OV, Dymecki SM (2020) A single-cell transcriptomic and anatomic atlas of mouse dorsal raphe Pet1 neurons. eLife 9:e55523.

Petreanu L, Mao T, Sternson SM, Svoboda K (2009) The subcellular organization of neocortical excitatory connections. Nature 457:1142-1145.

Pinault D (1996) A novel single-cell staining procedure performed in vivo under electrophysiological control: morpho-functional features of juxtacellularly labeled thalamic cells and other central neurons with biocytin or Neurobiotin. J Neurosci Methods 65:113-136.

Ren J, Isakova A, Friedmann D, Zeng J, Grutzner SM, Pun A, Zhao GQ, Kolluru SS, Wang R, Lin R, Li P, Li A, Raymond JL, Luo Q, Luo M, Quake SR, Luo L (2019) Single-cell transcriptomes and whole-brain projections of serotonin neurons in the mouse dorsal and median raphe nuclei. eLife 8:e49424.

Riemann D, Krone LB, Wulff K, Nissen C (2020) Sleep, insomnia, and depression. Neuropsychopharmacology 45:74-89.

Saper CB, Fuller PM, Pedersen NP, Lu J, Scammell TE (2010) Sleep state switching. Neuron 68:1023-1042.
Seo C, Guru A, Jin M, Ito B, Sleezer BJ, Ho YY, Wang E, Boada C, Krupa NA, Kullakanda DS, Shen CX, Warden MR (2019) Intense threat switches dorsal raphe serotonin neurons to a paradoxical operational mode. Science 363:538-542.

Sos KE, Mayer MI, Cserép C, Takács FS, Szónyi A, Freund TF, Nyiri G (2017) Cellular architecture and transmitter phenotypes of neurons of the mouse median raphe region. Brain Struct Funct 222:287-299.

Steiger A, Pawlowski M (2019) Depression and sleep. Int J Mol Sci 20:607.

Stuber GD, Wise RA (2016) Lateral hypothalamic circuits for feeding and reward. Nat Neurosci 19:198-205.

Szőnyi A, Mayer MI, Cserép C, Takács VT, Watanabe M, Freund TF, Nyiri G (2016) The ascending median raphe projections are mainly glutamatergic in the mouse forebrain. Brain Struct Funct 221:735-751.

Tamamaki N, Yanagawa Y, Tomioka R, Miyazaki J, Obata K, Kaneko T (2003) Green fluorescent protein expression and colocalization with calretinin, parvalbumin, and somatostatin in the GAD67-GFP knock-in mouse. J Comp Neurol 467:60-79.

Tsunematsu T, Ueno T, Tabuchi S, Inutsuka A, Tanaka KF, Hasuwa H, Kilduff TS, Terao A, Yamanaka A (2014) Optogenetic manipulation of activity and temporally controlled cell-specific ablation reveal a role for MCH neurons in sleep/wake regulation. J Neurosci 34:6896-6909.

Venner A, Anaclet C, Broadhurst RY, Saper CB, Fuller PM (2016) A novel population of wake-promoting GABAergic neurons in the ventral lateral hypothalamus. Curr Biol 26:2137-2143.

Venner A, De Luca R, Sohn LT, Bandaru SS, Verstegen AM, Arrigoni E, Fuller PM (2019) An inhibitory lateral hypothalamic-preoptic circuit mediates rapid arousals from sleep. Curr Biol 29:4155-4168.e4155.

Verret L, Goutagny R, Fort P, Cagnon L, Salvert D, Leger L, Boissard R, Salin P, Peyron C, Luppi PH (2003) A role of melanin-concentrating hormone producing neurons in the central regulation of paradoxical sleep. BMC Neurosci 4:19.

Vong L, Ye C, Yang Z, Choi B, Chua S Jr, Lowell BB (2011) Leptin action on GABAergic neurons prevents obesity and reduces inhibitory tone to POMC neurons. Neuron 71:142-154.

Weber F, Dan Y (2016) Circuit-based interrogation of sleep control. Nature 538:51-59.

Weissbourd B, Ren J, DeLoach KE, Guenthner CJ, Miyamichi K, Luo L (2014) Presynaptic partners of dorsal raphe serotonergic and GABAergic neurons. Neuron 83:645-662.

Xu M, Chung S, Zhang S, Zhong P, Ma C, Chang WC, Weissbourd B, Sakai N, Luo L, Nishino S, Dan Y (2015) Basal forebrain circuit for sleep-wake control. Nat Neurosci 18:1641-1647. 